\title{
Recent Advance in Anaerobic Co-digestion Technology: A Review
}

\author{
Andriamahefasoa Rajaonison ${ }^{1}$, Ives Abel Fetra Andriatsitohaina Rabesahala ${ }^{1} \&$ Hery Tiana \\ Rakotondramiarana ${ }^{1}$ \\ ${ }^{1}$ Institute for the Management of Energy (IME), University of Antananarivo, Antananarivo, Madagascar. \\ Correspondence: Andriamahefasoa Rajaonison, Institute for the Management of Energy (IME), University of \\ Antananarivo, Antananarivo, Madagascar.
}

Received: May 7, 2020

doi:10.5539/mas.v14n6p90
Accepted: May 28, 2020

Online Published: May 29, 2020

URL: https://doi.org/10.5539/mas.v14n6p90

\begin{abstract}
Due to their polluting characteristics, fossil fuels presently tend to be replaced by renewable energy resources. Anaerobic digestion is a recent technology for producing biofuels. As a biochemical method to produce biogas, it is more environmentally friendly than other processes and is almost non-polluting. The anaerobic co-digestion is an upgrade of the mono-digestion since some limitations of the single-substrate degradation were solved by digesting two or more substrates. The present review gives an overview of the progress made in the anaerobic co-digestion technology. Appearing as a complex technology, lots of factors can affect its operation. Those factors include the choice and the composition of the substrates, the ratio between the substrates and the inoculum, the pretreatment, the environmental conditions, the operational parameters, and the post-treatment at the end of the process. Analytical and empirical tools for the assessment of the whole system in terms of biodegradability and synergy of the substrates, the efficiency of the process, and the identification of the operation inhibitors are also presented in this paper.
\end{abstract}

Keywords: anaerobic co-digestion, biogas, bioreactor, post-treatment, pretreatment, synergistic effect

\section{Introduction}

Anaerobic digestion (AD) is a recent technology aiming for the substitution of fossil energy resources. In this process, organic wastes are degraded to produce biogas which is economically cheaper for heat and power production (Shahbaz, Ammar, Zou, Korai, \& Li, 2018) (Farhat, Miladi, Hamdi, \& Bouallagui, 2018) (Sarwar, Elbeshbishy, \& Parker, 2018). Used for food waste and organic solids treatment (Shahbaz et al., 2018) (Chan, Toledo, Iu, \& Shim, 2019) (Jiang et al., 2019), anaerobic co-digestion (AcoD) is the degradation of more than two substrates and has evidenced an efficient method when improving biomethanization of organic waste from various sources (Diego-Diaz, Cerdan, Penas, \& Fernandez-Rodriguez, 2018) (Cea-Barcia, Pérez, \& Buitrón, 2018).

The main drawbacks of mono-digestion include the disturbance and limitation of the fermentation process (Farhat et al., 2018) (Sukhesh, Muske, \& Rao, 2019). This limitation is caused by the lack of waste accessibility and complex composition (Farhat et al., 2018) (Rabii, Aldin, Dahman, \& Elbeshbishy, 2019). Furthermore, there are high solids content, large particle size, unequal nutrient composition, and low biodegradability of the single substrate (Sukhesh et al., 2019) (Siddique \& Wahid, 2018). It can also be mentioned the huge investment in biomass generation, the slow bioconversion rate of biogas, and the high sensitivity of methanogens (Siddique \& Wahid, 2018) (Tyagi et al., 2018) (Tong, Tong, \& Peng, 2019).

Consequently, AcoD was suggested to alleviate the lack of feedstock (Farhat et al., 2018). Moreover, it could facilitate the efficient use of the equipment and ensure the continuous supply of the feedstock (Tyagi et al., 2018). AcoD also improves the stability of the digester (Sukhesh et al., 2019) (Ahn, Lee, Kang, \& Kim, 2020), the process and its performance compared to mono-digestion (Berhe \& Leta, 2018) (Lovato, Albanez, Triveloni, Ratusznei, \& Rodrigues, 2018). Besides, AcoD permits to simultaneously stabilize the sludge and reduce its volume (Ahmad, 2020) (Glanpracha, Basnayake, Eldon R. Rene, \& Annachhatre, 2018). The use of AcoD also increases the Biomethane Potentials and improves the kinetic constant of biodegradability (Romagnoli, Dorella, Gruduls, Collotta, \& Tomasoni, 2019) (Fernández-Rodríguez, Lama-Calvente, Jiménez-Rodríguez, Borja, \& Rincón-Llorente, 2019) (Solé-bundó, Passos, Romero-güiza, Ferrer, \& Astals, 2019).

It should be mentioned that a mixture of diverse substrates increases nutrients through synergies established 
among different types of feedstock (Cea-Barcia et al., 2018) (Mozhiarasi et al., 2019). AcoD aims to favor beneficial interaction, limit inhibition, and increase methane production (Diego-Diaz et al., 2018) (Cea-Barcia et al., 2018) (Q. Yang et al., 2019).

Compared to mono-digestion, AcoD can favor weakening of toxicant compounds, rise in biodegradable organic matter (Vaidya, Boardman, Novak, Wimmer, \& Hanna, 2018) (Orfanoudaki, Maragkaki, Kallithrakas, \& Manios, 2019), economic benefits thanks to equipment sharing, diminished nutrient disproportion adjusting nitrogen and carbon contents, higher biogas production performance (Tong et al., 2019), and synergistic effect of microorganisms present in reactions easing the use of mixed substrates (Náthia-Neves, Berni, Dragone, Mussatto, \& Forster-Carneiro, 2018) (Gunes, Stokes, Davis, Connolly, \& Lawler, 2019).

Recent studies showed that cheese whey digested with cattle slurry using a single-stage anaerobic membrane bioreactor (AnMBR) arises as an advantageous method for water recovery (Ribera et al., 2020) since water scarcity is a widespread problem nowadays (Pradhan, 2017).

Moreover, Terada (2018) suggested co-digestion technology as a solution to the treatment of wastewater if its amount is reduced because of municipality depopulation.

In the AD process, there are four fundamental biochemical stages namely hydrolysis, acidogenesis, acetogenesis, and methanogenesis (Lovato et al., 2018) (Mehariya, Patel, Obulisamy, Punniyakotti, \& Wong, 2018) (Kougias $\&$ Angelidaki, 2018). The hydrolysis is assumed as the rate-limiting step in AcoD (Rabii et al., 2019) (Elalami et al., 2019) (Wickramaarachchi, Rathnasiri, Narayana, Torrijos, \& Escudie, 2019).

This paper presents the advance in AcoD technology including the different pretreatments used before the system operation, the reactor configurations, the environmental conditions of the process, the operational parameters, the different post-treatments, the methods of assessment of biodegradability and synergistic effect of substrates during AcoD, and finally the current inhibitors of biogas production in AcoD.

\section{Pretreatment}

Pretreatment could accelerate the hydrolysis process and improve the methane content in the biogas (Elalami et al., 2019) (Chuanchai \& Ramaraj, 2018). Besides, it facilitates the digestion process of raw materials (Li, Chen, $\& \mathrm{Wu}, 2019)$ by removing some barriers such as difficult or slow digestion by microorganisms, presence of inhibitors inside the feedstock (Elalami et al., 2019) (Martinez et al., 2018), and process-hindering elements generated throughout the biological processes (Achinas \& Euverink, 2019) (Alrawashdeh \& Al-Essa, 2019).

Apart from improving the biogas-generating process, pretreatments like pressure sterilization or pasteurization are ways to avoid pathogen dissemination in the environment in the case of anaerobic digestion of animal by-products (Tápparo, Amaral, Steinmetz, \& Kunz, 2019) (Wang, Jena, \& Das, 2018).

It should be mentioned that checking cellulose loading before digestion is important because the higher the cellulose content is, the lower is the rate of hydrolysis (Akshaya \& Jacob, 2020).

Currently, there are five types of pretreatment namely mechanical/physical, thermal, chemical, biological, and combined (Gunes et al., 2019) (Elalami et al., 2019) (Li et al., 2019) (M. Zhang et al., 2018).

\subsection{Physical Pretreatment}

Mechanical removal of inorganic compounds, for instance, plastics and metals, permits better use of the biodegradable compounds (Iacovidou \& Voulvoulis, 2018) (Fragoso, Carvalho, \& Duarte, 2020) and decreases the effects related to the use of conventional energy in mechanical separation (Colla et al., 2019). Screening pretreatment applied to sludge, for example, removes large constituents by using a grit chamber (Elalami et al., 2019). Then the size of the residues can be reduced to a particle by grinding or even turn to liquid to enhance the anaerobic digestibility of food residues but also to increase the solubilization (Cea-Barcia et al., 2018) (Iacovidou \& Voulvoulis, 2018) (Colla et al., 2019).

Mechanical pretreatment such as size reduction, comminution, or milling usually comes first in pretreatment operation, which is most of the time applied before other methods to ease and to induce a better effective process (Tyagi et al., 2018) (Colla et al., 2019) (Patinvoh, Lundin, Taherzadeh, \& Sárvári, 2020). Reduction of particle size might modify the composition inside the organic matter and decrease cellulose crystallization and polymerization to have better digestibility (Elalami et al., 2019) (Colla et al., 2019) (Venturin et al., 2019).

There are also microwave (Siddique \& Wahid, 2018) and ultrasound (Venturin et al., 2019) irradiations that change the biomass's cell wall structure, reduce cellulose crystallinity leading to increase biodegradability and improve process constancy, sludge dewaterability, solubilization of volatile solids, and biogas generation (Elalami et al., 2019) (Li et al., 2019) (Colla et al., 2019). Besides, it was found that the application of dosing 
additives like $\mathrm{H}_{2} \mathrm{O}_{2}$ or $\mathrm{CaO}_{2}$ helps in better use of microwave disintegration making microbes more accessible to their substrate (Li et al., 2019).

However, extrusion is mostly used to heat and shear humid biomass having an amount of moisture more than $15-20 \%$ and acts in defibrillation and shortening of fiber (Colla et al., 2019). Microbes can easily hydrolyze and digest lignocellulose-rich agricultural waste when the accessibility of the latter is better (Elalami et al., 2019) (Li et al., 2019).

In pyrolysis, in which temperature is higher than $300^{\circ} \mathrm{C}$, the decomposition of cellulose is quicker, leading to free gas in the raw material and the generation of coke-like residue (Martinez et al., 2018) (Colla et al., 2019).

Freezing pretreatment significantly increases the digestibility of lignocellulosic biomass enzyme while steam explosion, mostly implemented at full scale (Elalami et al., 2019), is one of the commonly used pretreatment methods to increase the degradability of lignocellulosic biomass (Colla et al., 2019) (Patinvoh et al., 2020).

The high-pressure homogenization is another method for the substrate pretreatment to reduce the feedstock particle sizes and to break up flocs in the reactor (Elalami et al., 2019) (Wang et al., 2018).

Plus, a microbial electrolysis cell combined with an iron-graphite electrode, magnetite, and zero-valent iron would be assumed to reduce the oxidation-reductive potential value of the feedstock resulting in a better environment for microorganisms ( $\mathrm{Li}$ et al., 2019).

Lysis Centrifuge, though, is a modified centrifuge which partially destroys sludge cells and/or dewaters sludge before AD (Elalami et al., 2019) (Hallaji, Kuroshkarim, \& Moussavi, 2019). Not only the substrate can undergo a pretreatment but also the inoculum which, for example, can partially be pre-concentrated by a centrifuge (E. Zhang et al., 2018).

Besides, pulsed electric field pretreatment can disrupt cell walls and solubilizes macromolecules as well as complex organic matters under high voltage (Elalami et al., 2019) (Li et al., 2019).

\subsection{Chemical Pretreatment}

\subsubsection{Acid Pretreatment}

The use of inorganic acids such as sulfuric, nitric, hydrochloric, and phosphoric acids and organic acids including formic, acetic, and propionic acids can dissociate and withdraw lignin from the raw material and hydrolyze plant fibers (Colla et al., 2019) (Venturin et al., 2019).

$\mathrm{Li}$ et al. (2019) showed that generated in hydrolysis, the D-configuration of monosaccharides can be easily converted into volatile fatty acids (VFAs), while the L-configuration of monosaccharides are harder to convert. However, the addition of cysteine facilitates its conversion as it can inhibit bacterial growth.

However, acid pretreatment was proved to be generally ineffective when breaking down lignin (Jacob-Lopes, Queiroz Zepka, \& Queiroz, 2018), excluding cases of high concentrations in the range of 30-70\%, and can avoid possible ammonia inhibition from the digestion of protein contained in the substrate (Gunes et al., 2019).

Nevertheless, pretreatment with acid is extremely dangerous when applied in industries because of corrosion risks. Furthermore, there is the risk of the formation of carboxylic acids, furans, and phenolic compounds which are inhibitors for microorganism development and the fermentation process (Gunes et al., 2019) (Horan, Yaser, \& Wid, 2018).

\subsubsection{Alkaline Pretreatment}

This pretreatment is better than acid pretreatment in terms of lignin solubilization and depends on the lignin contained in the biomass (Colla et al., 2019).

The conventional bases utilized in this type of treatment are sodium, calcium, potassium, magnesium (Tyagi et al., 2018) (Gunes et al., 2019) (Elalami et al., 2019), and ammonium hydroxides which increase porosity and inner surface area of the biomass, cause structural swelling, decrease polymerization and crystallinity, rupture the lignin structure, and break down lignin and other polymers (Wang et al., 2018) (Colla et al., 2019) (Wei et al., 2019).

Although, a drawback of alkaline pretreatment of the substrate is that it restricts the sulfate-reducing bacteria metabolism and the generation of hydrogen sulfate (Li et al., 2019).

\subsubsection{Wet Oxidation Pretreatment}

Always used to deal with lignin and hemicellulose, a mixture of water and an oxidizing agent such as air, oxygen, and hydrogen peroxide are put to the substrate, then the biomass is pretreated under high temperature between 
125 and $300^{\circ} \mathrm{C}$ and high pressure of 0.5 to $20 \mathrm{MPa}$. The duration of the pretreatment was deduced as the key factor in this pretreatment and can be just a few minutes to hours (Colla et al., 2019).

\subsubsection{Ionic Liquid Pretreatment}

In this pretreatment, the addition of N-methyl morpholine-N-oxide monohydrate, 1-n-butyl-3 methyl imidazolium chloride, 1-allyl-3-methyl imidazolium chloride, 3-methyl-N-butyl pyridinium chloride, or benzyl dimethyl (tetradecyl) ammonium chloride improves enzymatic digestibility (Colla et al., 2019) (Venturin et al., 2019) (Jingura \& Kamusoko, 2016). Moreover, chlorine is also used for the disinfection of substrate (Elalami et al., 2019).

Besides, additives namely mineral nutrients, metal oxide nanoparticles, bioaugmentation, increase methane production, and enhance process stability (Siddique \& Wahid, 2018) (Tyagi et al., 2018). Also, trace metals stimulate methanogenic activity such as nickel, iron, cobalt which were suggested as additives to enrich the medium (Rabii et al., 2019) (Li et al., 2019).

\subsubsection{Organosolv Method}

This pretreatment uses, for example, low-boiling alcohols which are organic solvents to chemically decompose the lignin fraction through breaking down ether bonds resulting in their dissolution (Colla et al., 2019) (Jingura \& Kamusoko, 2016).

\subsubsection{Ozonation Pretreatment}

Ozonation can disrupt cells and solubilize materials that are hard to break down. At higher doses, it mineralizes organic matter (Elalami et al., 2019). Furthermore, it can be used to destroy pathogens (Kalamdhad, Singh, \& Dhamodharan, 2016).

\subsubsection{Pre-hydrolysis Pretreatment}

Pre-hydrolyze the substrate like slaughterhouse waste was evoked to produce sulfide, which when precipitated with metal ions such as ferrous ion in advance to enter the digester, can prevent the inhibition of AD process by a too high concentration of hydrogen sulfide (Wang et al., 2018).

\subsection{Biological and Enzymatic Pretreatment}

Biomasses with high levels of lignin go through enzymatic pretreatments with enzymes such as laccase or peroxidase to improve the accessibility of cellulose. Thus, the crystallinity of the cellulose is reduced, its porosity enhanced, and eventually, the lignocellulosic materials are degraded (Shen et al., 2019) (Bhatnagar, Ryan, Murphy, \& Enright, 2019). This enables to increase biogas production, minimize carbohydrate loss, and maximize lignin removal (Colla et al., 2019). Other enzymes including peptidase, carbohydrase, lipase, cellulase, xylanase, and beta-glucanase or some type of bacteria like hydrolytic ones are also used (Gunes et al., 2019) (Li et al., 2019) (Bhatnagar et al., 2019).

Biological pretreatment mostly uses fungi or bio-surfactants, microbial consortium, and enzymes (Elalami et al., 2019) (Colla et al., 2019).

\subsubsection{Fungal and Microbial Consortium Pretreatment}

It was shown that fungi, namely brown, white, and soft-rot fungi selectively break down lignin as well as hemicellulose (Li et al., 2019) (Colla et al., 2019).

Microbial pretreatment, however, is executed by microorganisms taken from natural ecosystems. The microbes operate on a lignocellulosic substrate that has a high degradability of cellulose and hemicellulose (Colla et al., 2019). The combination of hemicellulose, cellulose, and lignin serves as a barrier to the microbial populations that hydrolyze cellulose (Wickramaarachchi et al., 2019) (Sittijunda \& Reungsang, 2020). It was found that combined with $\mathrm{H}_{2}$-using bacteria, propionic and/or butyrate acid oxidizing bacteria generate more acetic acid for acetogenic bacteria. Moreover, the addition of magnetite $\left(\mathrm{Fe}_{3} \mathrm{O}_{4}\right)$ eases the consumption of dihydrogen by the microorganisms ( $\mathrm{Li}$ et al., 2019). It should be noted that a long-term acclimation of microbes was proven to be a powerful method for improving the inoculum quality for AD of a given substrate (Kumar, Prajapati, Malik, \& Vijay, 2019) (Zealand et al., 2018) (Akshaya \& Jacob, 2020).

\subsubsection{Enzymatic Hydrolysis}

Enzymatic hydrolysis seems to be more interesting than the other methods. First, the consumption of water and energy is low. Then, waste use is cheaper, and it prevents from risks of equipment corrosion (Bhatnagar et al., 2019). 
The addition of one or a mixture of enzymes can increase substrate degradation (Venturin et al., 2019) (Bhatnagar et al., 2019). Enzyme acting on cellulose, hemicellulose, and starch are generally used for lignocellulosic feedstock (Colla et al., 2019) (Jacob-Lopes et al., 2018).

The use of enzymes is more beneficial for the environment. Moreover, the call for energy and chemicals is lower. Furthermore, the enzymes perform in a moderate condition decreasing the production of inhibitors ( $\mathrm{Li}$ et al., 2019) (Kalamdhad et al., 2016). On the other hand, even if it surpasses the weaknesses of chemical pretreatments, its treatment time is longer, and keeping the temperature constant throughout the process is more expensive (Gunes et al., 2019).

\subsection{Thermal Pretreatment}

Thermal pretreatment consists principally in the dispersion of cell membranes, and consequently the solubilization of organic compounds (Gunes et al., 2019) (Li et al., 2019). Thermal drying can also be a very attractive process for the reduction of substrate volume to enhance reactor volume and increase the volatile solids (VS) concentration (Alrawashdeh, 2019).

Moreover, the boiling pretreatment of grass substrate was shown to increase its biodegradability at $100^{\circ} \mathrm{C}$ with 2 hours of retention time (Chuanchai \& Ramaraj, 2018).

Besides, this pretreatment partially solubilizes but completely decontaminates sludge (Gunes et al., 2019). The suitable temperatures for sludge thermal pretreatment were suggested ranging between $150^{\circ} \mathrm{C}$ and $180^{\circ} \mathrm{C}$ under the pressure of 600-2 $500 \mathrm{kPa}$ and during 30-60 mn (Elalami et al., 2019).

Nevertheless, a high temperature above $110^{\circ} \mathrm{C}$ can be an inhibitor. In contrast, a long interaction time at a lower temperature can result in the production of complex and hard to degrade substrates, the melanoidins. This phenomenon is commonly linked to the chemical reaction between amino acids and carbohydrates also called the Maillard reaction (Gunes et al., 2019).

Above all, M. Yu et al. (2018) utilized an original pretreatment method called ethanol pre-fermentation. It has the benefits of the usual acidification-preventing methods resulting in the enhancement of methane yield and the conservation of anaerobic system stability.

However, Elalami et al. (2019) suggested a multi-criteria analysis scheme for the assessment of the real advantages of the pretreatment step. Looking only at the benefits of energy as the sole criterion of sustainability when applying a pretreatment is insufficient. Consequently, the advantages of a pretreatment step should be evaluated by looking at different aspects such as technical, microbial, sanitary for agronomic, environmental, and economic issues. Nevertheless, Tong et al. (2019) evoked the possible assessment of both the environmental, technical, economical as well as energy aspects of AD technology using life cycle assessment (LCA).

\section{Reactor}

The choice of an appropriate reactor configuration was shown to be a decisive factor for improving biogas production (Lovato et al., 2018) (Mehariya et al., 2018). In fact, in AD, the reactors should enable a high and constant feed of substrate or organic load rate (OLR), a short hydraulic retention time (HRT), and also permit a high biogas yield (Náthia-Neves et al., 2018) (Sahoo \& Rao, 2019).

Until now, there are 4 types of reactors used for an $\mathrm{AD}$ process namely single-phase reactors, multiphase reactors, batch reactors, and continuous or semi-continuous reactors (Náthia-Neves et al., 2018) (Gunes et al., 2019). While being more expensive in manufacture and maintenance than single-phase reactors, multiphase reactors are commonly utilized as they are more efficient (Rabii et al., 2019) (Náthia-Neves et al., 2018).

In single-phase bioreactors, the acidogenic and methanogenic phases operate in a single reactor, whereas in multiphase schemes more than one reactor is involved, usually two, in which the principal steps of the AD process are separated (Náthia-Neves et al., 2018) (Horan et al., 2018). Continuous reactors, on the other hand, require long periods of start-up and are inadequate for wastewaters inoculated with low organic load (Lovato et al., 2018). Moreover, there is the risk of extraction of partially digested matter during the effluent removal from the digester. However, in continuous reactors, chemical reactions are possible at a rate more or less constant leading to a stable biogas generation (Náthia-Neves et al., 2018). Besides, in batch mode, reactors appear to be more flexible (Gunes et al., 2019), with cheaper installation, are more secure, and can maintain a high quality of the effluent (Lovato et al., 2018). However, its disadvantages are high variations in biogas production and quality, but also biogas losses when the reactors are discharged (Náthia-Neves et al., 2018).

Two-phase systems seem to be more efficient for AD of a mixture of wastes (Farhat et al., 2018) (Náthia-Neves et al., 2018) (Berhe \& Leta, 2019). In such a system, the first phase intends to improve the hydrolysis and 
acidogenesis steps (Q. Yang et al., 2019) (Liu \& Liao, 2018) which rate is hindered by the hydrolytic reaction of complex carbohydrates (Náthia-Neves et al., 2018). Then, the second phase intends to improve the acetogenesis and methanogenesis reactions (Liu \& Liao, 2018). Instability of the environment in a reactor occurs when acidogenic and methanogenic microbes are in the same reactor ( $\mathrm{Li}$ et al., 2019). Isolation of two varieties of bacteria in two different reactors with their respective functions would promote the digestion rate and stabilize the biochemical process (Rabii et al., 2019) (Li et al., 2019). As reported in the literature, the optimum operating conditions in the first reactor (hydrolysis-acidogenic) should be at a low HRT of 2 to 3 days and in a pH within 5-6. This aims for the maximum total volatile fatty acids (TVFA) production rate to achieve a level of acidification within $20-40 \%$. Consequently, the activity of the methanogenic reactor installed immediately next to the first one increases. The second reactor, however, usually operates with an HRT within 20 to 30 days and a $\mathrm{pH}$ value of 6 to 8 facilitating the evolution of slowly developing methanogenic archaea (Rabii et al., 2019) (Berhe \& Leta, 2019).

Therefore, the advantages of a three-phase digester over single and two-phase configurations were proven by the use of a recent compact three-stage anaerobic digester in which hydrolysis, acidogenesis, and methanogenesis occurred in three distinct regions (Rabii et al., 2019). Besides, it was shown that this configuration significantly accelerates the solubilization of the solid fraction of organic matters and the formation of VFAs inducing methane yield enhancement (Rabii et al., 2019) (J. Zhang et al., 2017).

\subsection{The Continuous Stirred-tank Reactor (CSTR)}

CSTRs were appropriate when processing a big quantity of suspended solids (Kougias \& Angelidaki, 2018), with twice to thrice more performant than low rate digesters, and unstirred or intermittently stirred reactors (Gunes et al., 2019). In CSTRs, the presence of an agitator enables the contact between microbes and the substrate (Gunes et al., 2019), protecting the reactor from the sedimentation of inside solids and increasing mass transfer (Berhe \& Leta, 2019). It grants the liberation of gas bubbles trapped in the medium (Náthia-Neves et al., 2018).

It was depicted that the stirring speed is the restricting factor for hydrogen generation using a CSTR (Náthia-Neves et al., 2018). It was proved that optimum speed is at $50 \mathrm{rpm}$ (Tišma et al., 2018). Excessive stirring would be negative to biogas generation because microbial granules are disrupted in their structure (Latha, Velraj, Shanmugam, \& Sivanesan, 2019). Besides, too much stirring lowers the oxidation of fatty acids (Ahlberg-Eliasson, Liu, Nadeau, \& Schnürer, 2018). Hence, they cumulate in the reactor, resulting in the acidification of the digestate and consequently inhibit the AD process (Náthia-Neves et al., 2018).

\subsection{Fixed Bed Reactor}

Fixed bed reactors, apart from its expensive investment and energy cost, are noticeable by low hydraulic turbulence which hinders mass transfer for the static cells so that both substrate conversion and hydrogen generation are reduced (Náthia-Neves et al., 2018). Thus, the recirculation of the biomass is a solution to enhance the production rate and product yield by reduction of mass transfer resistance (Zhou \& Wen, 2019).

\subsection{Upflow Anaerobic Sludge Blanket (UASB) Reactor}

This digester configuration is convenient for effective domestic wastewater treatment (Vassalle et al., 2019). Few important benefits of the UASB reactor include the stability of biogas production time, low energy demand, excellent removal performance at low temperatures, sustainable decay-prevention of inoculum, good mixing, and low sludge generation (Gunes et al., 2019) (Lovato et al., 2019) (Franchi, Cabrol, Chamy, \& Rosenkranz, 2020).

Its drawbacks are the long starting period, the great number of microorganisms in the wastewater, the need for strict temperature control, partial removal of pathogens, the high solid retention time (SRT), and working with comparatively low OLR (Náthia-Neves et al., 2018) (H. Chen et al., 2020).

\subsection{Expanded Granular Sludge Blanket Reactor}

This new variation of UASB has more benefits than a usual UASB thanks to the utilization of granular sludge, better mixing, and little bed extension because of a greater upflow velocities around $4-10 \mathrm{~m} \cdot \mathrm{h}^{-1}$ against $0.6-1.79$ $\mathrm{m} . \mathrm{h}^{-1}$, and better mass transfer amongst substrate and sludge aggregates owing to enhanced stability of granular biofilms (Gunes et al., 2019). Compared to the UASB reactor, hydrodynamics was improved by processing higher organic and hydraulic loadings (Franchi et al., 2020) (Ijanu, Kamaruddin, \& Norashiddin, 2020). Moreover, it can process lipids, and harmful or hindering contents in wastewaters and acidify wastewaters under psychrophilic conditions (Gunes et al., 2019). However, its drawbacks are a bad removal of suspended solids (Gunes et al., 2019), and does not remove nitrogen and phosphorus nutrients (Ijanu et al., 2020). 


\subsection{Fluidized Bed Reactor}

Suitable for processing soluble material or for suspended and readily biodegradable feed material, this type of reactor allows high SRT, good mixing within the reactor, and suitable mass transfer within the microbial biomass and the wastewater (Náthia-Neves et al., 2018). Also, it is interesting for its economic viability owing to the decreased volume of the reactors (Jingura \& Kamusoko, 2016).

\subsection{Plug Flow Reactor}

The presence of impeller minimizes stratification in the reactor; and the reduction of mixing in the reactor allows good interaction between the microbes and the feedstock, enhancing the degradation rate and the methane production (Patinvoh et al., 2020).

Initial investments for the installation and start-up of the reactor are lower than that of the other reactors because the plug flow reactor does not have internal moving parts. Also, it generally necessitates reduced computer control and human assistance (Dong et al., 2019).

\subsection{Single-stage Anaerobic Membrane Bioreactor}

This kind of reactor, usually utilized to treat wastewater (Terada, 2018), permits the dissociation of sludge retention time and HRT, favoring the process at high OLRs in smaller reactors and enable its further reuse (Ribera et al., 2020). While membrane fouling is its principal weakness, a microbial electrolytic cell biosystem was constructed to tackle that (Du et al., 2019).

AnMBR should be properly working with short HRT, with high SRT, and at low temperatures because almost absolute biomass retention can be reached in the digester compared to usual ones (Gunes et al., 2019).

\subsection{Anaerobic Sequencing Batch Biofilm Reactor (AnSBBR)}

Previous works showed that the use of an AnSBBR containing immobilized biomass and mechanical agitation operating in fed-batch mode is an alternative to small and medium waste producers in the agriculture and food industries. They can expect a more appropriate structure considering the kind of feeding method and influent concentration (Lovato et al., 2018) (Lovato et al., 2019).

\subsection{Leach Bed Reactor}

Leachate is particularly important in the biogas production rate as it better disperses microbes and raw material, and improves mixing (J. Yu et al., 2019). Hence, this reactor is not equipped with a stirring tool (J. Yang, Wang, Luo, Zeng, \& Huang, 2020), or high-pressure tanks, which consequently reduces the investment prices (Gunes et al., 2019). Nevertheless, what should be addressed are the relative heterogeneity in the reactor, clogging, and process execution difficulty (J. Yang et al., 2020).

\subsection{Solid-state Anaerobic Digestion (SS-AD) Reactor}

This reactor is believed to be more appropriate for lignocellulosic matter and can process feedstock with high solid fraction usually at 15 to $40 \%$ of total solids (TS) content (Gunes et al., 2019) (Zhou \& Wen, 2019).

The substrate to inoculum (S/I) ratio undergoes regular optimization for SS-AD because it is viewed as the key factor for enhancing methane production and stability of the reactor in batch mode. Besides, a good S/I ratio helps achieve a proper specific methane production rate and a volumetric methane production rate balance (Ma et al., 2019).

The advantageous aspects of SS-AD compared to liquid anaerobic digesters are a treatment of more organic matter within an identical digester volume, smaller energy consumption for heating and digestion procedure, and lower outflow generation (Gunes et al., 2019) (Ma et al., 2019). Furthermore, SS-AD can produce methane 2 to 7 times more than a liquid-state process (Gunes et al., 2019). Nevertheless, the principal weaknesses hindering the effectiveness of this reactor are long SRT, insufficient mixing, and an accumulation of inhibiting compounds (Zhou \& Wen, 2019).

\subsection{Anaerobic Sequential Batch Reactor (ASBR)}

The ASBR commonly operates following a fill-and-draw treatment cycle with four phases including loading, reaction, settling, and emptying (Franchi et al., 2020). A good mixing in organic matter settling influences the system efficiency thanks to a stirrer or a medium recirculation, to guarantee enough mass transfer throughout the process (Gunes et al., 2019). 


\subsection{Anaerobic Flter Reactor (AFR)}

This biodigester ameliorates the contact within the digestate and the bacterial consortium due to the attached support media, improving methane fermentation efficiency (Y.-T. Chen et al., 2020). With the possibility of running either in an upflow or downflow configuration, recycling and upflow pathway is usually adopted for processing extremely complex materials. Nevertheless, the possible clogging of the media is the weakness of this reactor (Gunes et al., 2019).

\section{Environmental Conditions}

\section{$4.1 \mathrm{pH}$}

It was proven that $\mathrm{pH}$ is a significant indicator for assessing the stability of $\mathrm{AD}$ systems (E. Zhang et al., 2018) (Berhe \& Leta, 2019). Anaerobic microorganisms responsible for the AD operation process need different $\mathrm{pHs}$ to grow optimally. Consequently, pH affects the digester operation (Náthia-Neves et al., 2018) (Achinas \& Euverink, 2019).

The level of $\mathrm{pH}$ in the bioreactors depends on the production and use of acid and alkalinity (Sarwar et al., 2018) (Uma, Thalla, \& Devatha, 2020).

Values of $\mathrm{pH}$ between 5.5 and 6.5 were found to be optimal for hydrolytic bacteria and acidogenic microorganisms (Gunes et al., 2019) (Achinas \& Euverink, 2019) (Berhe \& Leta, 2019) (Uma et al., 2020). Therefore, neutral $\mathrm{pH}$ in the range of 6.8-7.7 is more suitable for the excellent metabolism and growth of methanogens (Lovato et al., 2018) (Mehariya et al., 2018) (Elalami et al., 2019). The growth rate of methanogens is affected in reactors with a $\mathrm{pH}$ value of less than 6.6 , whereas a $\mathrm{pH}$ around 8 could disintegrate microbial granules, and consequently, the process may fail. However, the optimal $\mathrm{pH}$ for the methanogenesis step is commonly around 7 (Náthia-Neves et al., 2018) (Gunes et al., 2019) (Patinvoh et al., 2020) (Uma et al., 2020).

\subsection{Temperature}

This parameter can induce notable impacts on microbial consortiums, affecting the stability of the process, the microbial development, the substrate processing rate, and the biogas yield (Náthia-Neves et al., 2018) (Gunes et al., 2019) (Li et al., 2019).

There are five types of temperature at which AcoD can operate viz. psychrophilic (approximately $25{ }^{\circ} \mathrm{C}$ ), mesophilic (approximately $35^{\circ} \mathrm{C}$ ), intermediate (approximately $42^{\circ} \mathrm{C}$ ), thermophilic (approximately $55^{\circ} \mathrm{C}$ ) (Diego-Diaz et al., 2018) (Siddique \& Wahid, 2018) (Jingura \& Kamusoko, 2016) and hyperthermophilic $\left(>60^{\circ} \mathrm{C}\right)$ (Q. Yang et al., 2019) (Sahoo \& Rao, 2019).

Under psychrophilic temperatures, chemical and biological reactions take place slower, in contrast to thermophilic temperatures, in which the metabolism of microbes enhances (Horan et al., 2018) (Sahoo \& Rao, 2019).

Mesophilic conditions are commonly adopted in anaerobic digesters (Horan et al., 2018) for biogas production because good digestion can be obtained with a little amount of energy (Sahoo \& Rao, 2019). Moreover, mesophilic conditions allow better stability of the AD (Sahoo \& Rao, 2019), and environmental fluctuations have less impact on the process (Siddique \& Wahid, 2018). It was found that AcoD in mesophilic conditions permits a greater possibility of a mixture of different kinds of substrates (Rabii et al., 2019). However, microbes working at the mesophilic temperature are more impacted by ammonia accumulation than microbes operating at thermophilic conditions (Náthia-Neves et al., 2018) (Gunes et al., 2019).

Thermophilic conditions are usually utilized in large-scale configurations (Kalamdhad et al., 2016) (Algapani et al., 2019). Also, thermophilic temperatures or raising of temperature ensure higher rates of pathogen destruction (Li et al., 2019) (Sahoo \& Rao, 2019). Therefore, high temperatures call for more energy investment, and higher process control to reach consistent and invariant temperature in the reactor. Moreover, thermophilic conditions could help in the acid formation in the bioreactor, constraining biogas production as a result (Náthia-Neves et al., 2018) (Uma et al., 2020).

It was asserted that a switch from mesophilic to thermophilic conditions may decrease the biogas generation since the microbes adapt to the substrate and resulting in a growth of the number of microbial populations (Náthia-Neves et al., 2018). However, an increase of biogas yield was found while co-digesting food waste with rice husk by using temperature-phased reaction, meaning at two temperature regions, thermophilic and mesophilic (Sahoo \& Rao, 2019).

In general, biomethanization is executed at a mesophilic or thermophilic temperature which both can influence 
the process (Jingura \& Kamusoko, 2016) (Sahoo \& Rao, 2019). However, more attention should be put on AcoD operating under thermophilic conditions than that of mesophilic processes (Mehariya et al., 2018) (Elalami et al., 2019).

It was also shown that the thermophilic process gives more effective biomethane potential than mesophilic. In a thermophilic temperature the operation time is shorter and the utilization rate of the substrate organic fraction is more efficient improving nutrients for microorganisms throughout fermentation (Uma et al., 2020) (Ngan, Chiem, Nam, Viet, \& Ingvorsen, 2019).

\subsection{Moisture Content}

The moisture content (on TS concentration basis) defines the type of anaerobic digestion method viz. wet, semi-dry/hemi-solid, and dry/solid for biogas generation (Rabii et al., 2019) (E. Zhang et al., 2018). AD is usually wet, semi-dry, or dry when the quantity of TS of the substrate is respectively under $10 \%$, between 10 $15 \%$, or more than $15 \%$ (E. Zhang et al., 2018) (Ma et al., 2019).

Wet $\mathrm{AD}$ is commonly used to deal with livestock and poultry breeding wastewater, energy crop, and food waste owing to increased methane yield based on the mass of substrate, less quantity of generated sludge, and suitable functioning and care (E. Zhang et al., 2018).

Dry anaerobic digestion, however, is a better choice for biomass with low moisture content, including crop straw and municipal sludge due to the low quantity of water needed, little reactor requested, and increased quantity of methane yield (Wickramaarachchi et al., 2019) (E. Zhang et al., 2018) (Ma et al., 2019). Moreover, the management of anaerobic sludge activity was found to help speed up the start-up of dry anaerobic digestion reactors and address the need for a great quantity of activated sludge (E. Zhang et al., 2018).

Nevertheless, it was observed that the greatest level of methane generation could be reached in processes with a great level of moisture content (Akshaya \& Jacob, 2020) (Latifi, Karrabi, \& Danesh, 2019).

\subsection{Carbon-to-nitrogen (C/N) Ratio}

This is an important factor in the $\mathrm{AD}$ process and is dependent on carbon- and protein-rich substrates (Akshaya \& Jacob, 2020) (Salama et al., 2019). The balance of the $\mathrm{C} / \mathrm{N}$ ratio of the feedstock was shown to enhance the methane production of anaerobic co-digestion (Mozhiarasi et al., 2019) (Zealand et al., 2018) (Ngan et al., 2019). The proportion between carbon and nitrogen improves the buffering capacity and minimizes the effect of inhibitory compounds (accumulation of organic acids, ammonia, VFAs) (Elalami et al., 2019) (Fragoso et al., 2020) (Shen et al., 2019) (Sahoo \& Rao, 2019).

Supplement of carbohydrates enhances protein transformation and performance of proteases in the medium while nitrogen is crucial for protein synthesis which is a nutrient for the microbes in charge of anaerobic digestion reactions (Náthia-Neves et al., 2018) (Hallaji et al., 2019). Nitrogen, in the form of ammonia after conversion in AD (Patinvoh et al., 2020) (Akshaya \& Jacob, 2020), helps to maintain constant the pH level in the digester throughout the process (Náthia-Neves et al., 2018) (Latifi et al., 2019).

$\mathrm{C} / \mathrm{N}$ ratios of approximatively 20 to 30 were shown to be suitable for $\mathrm{AD}$ of urban solid waste organic matter (Náthia-Neves et al., 2018) (Elalami et al., 2019) (Colla et al., 2019) (Hallaji et al., 2019). Besides, a range of approximately 15-30 was used for anaerobic digestion in general (Mozhiarasi et al., 2019) (Achinas \& Euverink, 2019) (P. Kumar et al., 2019) (Zealand et al., 2018) (Sahoo \& Rao, 2019) (Ferreira, Jr, \& Cammarota, 2018).

Use of carbonaceous substrates or fat, oil, and grease (FOG) which are rich in carbon were suggested with wastewater sludge to enhance the efficiency of digesters because sludge as the sole substrate shows low $\mathrm{C} / \mathrm{N}$ ratio (Elalami et al., 2019) (Hallaji et al., 2019) (Salama et al., 2019). Moreover, the bacterial population structure resulted in a dynamic change when introducing FOG residues to a reactor (Rabii et al., 2019).

\subsection{Microbial Community}

The microbial community in the biogas process is important (Achinas \& Euverink, 2019) since it was suggested that specific dominant operational taxonomic units might be more significant to methane production than a variety of microorganisms (Zealand et al., 2018). The addition of co-substrate may bring in many variate species (Rabii et al., 2019) that do not correspond to methane generation itself but more associated with intermediate reactions (Latifi et al., 2019).

Furthermore, the decline of the digestion process and low methane production could be induced by the bad proportion of methanogenic archaea and the microorganisms responsible for the hydrolysis, the acidogenesis, and the acetogenesis (Ma et al., 2019). 
The 16S rRNA gene-based fingerprints method was promoted to recognize and compare microbes in an appointed sample (Wei et al., 2019). It would be a suitable method for analyzing microorganisms' consortiums or environments that are complicated or not possible to examine. Therefore, it provides minus slanted and the most information possible and supports a lot of unfamiliar aspects regarding the process of microorganism reaction to the reactor improvement (Rabii et al., 2019).

It was suggested that controlling qualitative and quantitative adjustments in a microorganism population configuration by the influence of temperature, OLR, and substrate mixture enables to evaluate the effect of the co-substrate on microbes' communities helping the biogas generation (Rabii et al., 2019) (Muske \& Rao, 2019).

Feedstock accessibility by using various biomass sources and environmental parameters was confirmed to be the principal factor impacting the evolution of the microbe population in the case of an AcoD in mesophilic conditions (Wei et al., 2019) (Ma et al., 2019).

The major abounding community of very active methanogens found in AcoD processes is Methanosaeta, species of the archaeal consortium, and can generate a big volume of methane (Ma et al., 2019).

It was evidenced that the key pathway for producing methane is hydrogen transfer within methanogenic bacteria and archaea consortiums through syntrophic metabolism (Rabii et al., 2019).

Then, possible modeling of the microbial growth was suggested by using the kinetics of Monod (Siddique \& Wahid, 2018) whose equation was later improved to better fit the experimental data (Gaibor-Chávez, Niño-Ruiz, Velázquez-Martí, \& Lucio-Quintana, 2019).

The VFAs concentration was demonstrated to be excellent to indicate an excess of the microbe community (Kalamdhad et al., 2016). Nevertheless, alkalinity and pH seem to be good indicators, too (Rabii et al., 2019).

\section{Operational Parameters}

\subsection{Hydraulic Retention Time}

The processing parameter HRT is considered as one of the key parameters of AD operation because it affects biogas productions as well as system effectiveness for either batch or continuous modes (Gunes et al., 2019) (Carminati et al., 2018). It is linked to the temperature of the system and the composition of the substrate (Náthia-Neves et al., 2018).

Digesters operating at low HRT can experience an important increase in biogas production (Latifi et al., 2019) due to the degradation of the co-substrate (González, Smith, Blanco, Fierro, \& Gómez, 2019). However, if the hydraulic retention time is not long enough to allow the generation of microorganisms, the latter can be removed (Li et al., 2019), and therefore causes the inhibition of the AD process (Siddique \& Wahid, 2018) (Salama et al., 2019). In contrast, long HRT has risks of microbe death due to the deficit of nutrients (Siddique \& Wahid, 2018). Nevertheless, in the case of thermophilic conditions, decreasing the HRT was not favorable to specific gas production (Qi \& Chapman, 2018).

The HRT for microbes operating at mesophilic temperatures commonly values from 10 to 40 days, and for microbes operating at thermophilic conditions about 14 days (Náthia-Neves et al., 2018) (E. Zhang et al., 2018) (Uma et al., 2020).

\subsection{Solid Retention Time}

The SRT parameter also affects AD performance (Dosta et al., 2018). The microorganisms are partially taken away every time the sludge is removed. However, it can be tackled by a balance between cell growth and cell withdrawal to keep an unvarying condition, and to avoid process inhibition. Usually, SRT between 10-40 days is adopted, otherwise, it could affect the digester performance (Rabii et al., 2019).

\subsection{Organic Loading Rate}

The OLR is also considered as among the key operational parameters of AD as it affects biogas production (Jingura \& Kamusoko, 2016) (Latha et al., 2019), and the system performance (Rabii et al., 2019) for either batch or continuous scheme (Gunes et al., 2019).

Studies showed that low OLR results in a noticeable reduction of the reactor volume (Rabii et al., 2019), and consequently, the system's total economy gets better. In contrast, high OLR may compromise the process stability ensuing in inhibition of the AD. Firstly, substrate and VFAs accumulate (Rabii et al., 2019) (Gunes et al., 2019) because they might need more extended HRT for suitable operation. Besides, high OLR inhibits anaerobic microflora substrates (Náthia-Neves et al., 2018) (Elalami et al., 2019) (Li et al., 2019) (P. Kumar et al., 2019).

However, other studies deduced that slower OLR affects the effectiveness of the anaerobic digestion technology 
(Horan et al., 2018), whereas greater OLR favors the growth of various microbial species, demands lower energy consumption for heating, and minimizes the required tank volume and digester expense (Siddique \& Wahid, 2018). Consequently, it was suggested that the maximum value of OLR for high moisture content AD is 3.5 kgVS. $\mathrm{m}^{-3}$. day ${ }^{-1}$ (Borowski \& Kucner, 2019).

Above all the aforementioned parameters, the use of $\mathrm{pH}$ measuring combined with measuring of the alkalinity as partial alkalinity or VFAs was suggested for AcoD process monitoring (Rabii et al., 2019) (Kougias \& Angelidaki, 2018).

\section{Post-treatment}

According to the final use, the biogas may go through post-treatment or upgrading to achieve the natural gas specifications (Achinas \& Euverink, 2019). Biogas upgrading consists of purifying methane (Horan et al., 2018) and distribution through a gas network for users and transport (Elalami et al., 2019).

The purification after biogas production was found to enhance the methane content by microalgae pass biological purification (Chuanchai \& Ramaraj, 2018) to fix $\mathrm{CO}_{2}$ or using sulfur-reducing bacteria, reaction with activated biochar as adsorbents (Horan et al., 2018) for carbon dioxide and hydrogen sulfide elimination, and methanation or the injection of dihydrogen to react with carbon dioxide and produce methane (Elalami et al., 2019).

Besides, the biogas necessitates to be cleaned through desulfurization processes to remove the hydrogen sulfide, nitrogen, and carbon dioxide. There are processes like biological procedure in anaerobic digester operating on a full scale, cryogenic distillation, water and amine scrubbers, membrane gas permeation, or pressure swing adsorption (Gunes et al., 2019) (Elalami et al., 2019) (Wang et al., 2018). Gaseous hydrogen sulfide may be generated together with biogas (Gunes et al., 2019) and converted into sulfuric acid by oxidation when transported and utilization of biogas, resulting in the corrosion of pipelines and machine (Wang et al., 2018). Moreover, hydrogen sulfide smells like rotten-egg and is extremely harmful even at the small quantity of 100 ppm, which is dangerous for human health (Wang et al., 2018) (Akshaya \& Jacob, 2020).

Finally, bioelectrochemical systems are also utilized to enhance biogas produced by using the electromethanogenesis process. Carbon dioxide is reduced into methane thanks to electrons directly transferred from the cathode to methanogenic microorganisms (Elalami et al., 2019).

\section{Assessment of Biodegradability and Synergistic Effect of the Substrates during Co-digestion}

The operation of the AD process may be assessed with kinetic models (Wickramaarachchi et al., 2019).

Firstly, the anaerobic digestion model no.1 (ADM1 model) considers the balance between carbon and nitrogen of the digestate, reaction kinetic for bacterial decomposition and biomass digestion, reactor hydrodynamic, and some possible inhibitors including VFAs, dissolved hydrogen, and ammonia (Siddique \& Wahid, 2018) (Gunes et al., 2019). However, the ADM1 model appears to be inconvenient for dry anaerobic digestion of lignocellulosic biomass since initial ADM1 was used for CSTR, and the mass transfer coefficients are employed to liquid anaerobic digestion (Wickramaarachchi et al., 2019).

Secondly, the first-order kinetic model is commonly utilized by taking into account the proportion between methane production and the organic volatile solids present in the effluent (Akshaya \& Jacob, 2020). The biogas production rate constant in the model can indicate the biodegradability of the digestate that depicts the hydrolysis effectiveness and metabolism (E. Zhang et al., 2018). Nevertheless, it was experienced that the experimental determination of the maximum biogas potential parameter of the substrate needs a big amount of time as the entire VS in the biodigester should be used (Akshaya \& Jacob, 2020).

Moreover, the modified Gompertz model helps to evaluate the amount of cumulative biogas or cumulative methane of a bioreactor in batch mode (Wickramaarachchi et al., 2019). This model is suited for the performance assessment of the system and relies: on the hypothesis that the methane production from AD depends on microbial growth, and on the assumption that the rate of biogas production adopts a sigmoid curve (Wickramaarachchi et al., 2019) (Akshaya \& Jacob, 2020). Furthermore, this model was proved to be an excellent empirical non-linear regression model, and conventionally utilized in the estimation of methane yield (Wickramaarachchi et al., 2019) (Sukhesh \& Rao, 2018).

Besides, the mathematical modified first-order model is also usually adopted in the estimation of the whole AD process, including parametric quantities for conversion constant, and ultimate methane production (E. Zhang et al., 2018). And less famous, the Chen and Hashimoto model (Sukhesh \& Rao, 2018) and the cone model (Achinas \& Euverink, 2019) are also used for the kinetic analysis of the AD. 
Apart from the kinetics model, other methods including specific energy-loading rate where the reactor is stable below 0.4 day $^{-1}$ (Fragoso et al., 2020), thermal analysis, and the differential scanning calorimetry are also used to assess the AD stability (González et al., 2019).

Furthermore, the anaerobic Digestion Performance Index (DPI) is utilized to find out the relationship within biomethane potential reached and the organic load (Uma et al., 2020). DPI is applied to identify the effect on the efficiency of the process when the substrates are mixed (Sittijunda \& Reungsang, 2020) (Akshaya \& Jacob, 2020). The DPI is established on synergistic, antagonistic, and independent interactions (Akshaya \& Jacob, 2020) which are associated with the S/I ratio (Sittijunda \& Reungsang, 2020) (Uma et al., 2020). This index is computed with the proportion of experimental biomethane yield to the theoretical biomethane potential obtained on the percentage of VS. Hence, DPI $>1$ shows the synergistic effect, DPI $<1$ designates an antagonistic effect, and DPI $=1$ means a substrate that evolves separately from the combination (Akshaya \& Jacob, 2020) (Uma et al., 2020).

The synergistic effect of co-digestion can also be determined by the weighted average of the individual methane yield of each substrate or the weighted experimental methane yield (weighted EMY) (Bhatnagar et al., 2019). When the difference EMY - the standard deviation absolute value is greater than the Weighted EMY, there is a synergistic effect (E. Zhang et al., 2018) (Bhatnagar et al., 2019).

The determination of biodegradability can be made by the comparison of calculated and measured biogas yields (Mozhiarasi et al., 2019).

Moreover, Oliveira et al. (2018) used a Central composite design circumscribed (CCC) to determine the experimental conditions of anaerobic biodegradability. CCC is a five-level factorial design and a response surface methodology having the following characteristics: (i) enabling the analysis of the effect of independent variables (e.g.: main substrate concentration, co-substrate concentration), and various interactions among them into the response variables of the process ( e.g.: cumulative methane production and methane production rate), but also (ii) aiming to optimize the latter.

Besides, the biodegradability can be analyzed by the balance in the chemical oxygen demand (COD) of the substrate before and after the anaerobic treatment is performed (Gaibor-Chávez et al., 2019). Moreover, another method to determine the biodegradability would be based on the degradation of organic carbon (Akshaya \& Jacob, 2020).

The Biochemical methane potential (BMP) test of the substrates is still a method commonly used to calculate the theoretical biogas production from the mixtures of substrates and to evaluate synergies in the co-digestion system (Tápparo et al., 2019) (P. Kumar et al., 2019) (González et al., 2019). A synergy index, $\alpha_{B M P}$, is computed by the ratio of the BMP values in the co-digestion conditions with the theoretically computed value of the mono-digestion (Romagnoli et al., 2019).

The theoretical biomethane potential and the technical biomethane potential were also used to estimate biomethane potential from the $\mathrm{AD}$ of organic waste (Wang et al., 2018).

However, the optimum substrate ratio was determined by calculating a critical $\mathrm{CH}_{4} / \mathrm{CO}_{2}$ factor (Inayat et al., 2019). Besides, response surface methodology with central composite design was used to optimize the co-substrates concentrations and the inoculum concentration (Sittijunda \& Reungsang, 2020).

\section{Inhibitors of Biogas Production}

The accumulation of VFAs, ammonia, and $\mathrm{H}_{2} \mathrm{~S}$ are examples of factors that lead to the failure of the digestion (Vaidya et al., 2018) (Ribera et al., 2020) (Elalami et al., 2019) (González et al., 2019). It was asserted that extremely high soluble COD may lead to the accumulation of VFAs, making a delay in biogas production, or reducing the $\mathrm{pH}$ of bioreactors (Hallaji et al., 2019).

Furthermore, ammonia nitrogen can strongly inhibit the $\mathrm{AD}$ system and may ease the disturbance of the process (Shen et al., 2019) (Berhe \& Leta, 2019) (Song et al., 2019). High ammonia concentrations could cause serious inhibition of specific enzyme responses and microbial growth in aqueous AD (Achinas \& Euverink, 2019) (Wang et al., 2018) (E. Zhang et al., 2018). The recommended limit of the amount of ammonia 1.7-1.8 g.L $\mathrm{L}^{-1}$ of the reactor was found (Fragoso et al., 2020) (Borowski \& Kucner, 2019). Therefore, operating with suitable characteristics, porous biochar was used to absorb ammonia (Horan et al., 2018), decrease its inhibitory effect, and immobilize methanogenic microorganisms (Li et al., 2019).

The alkalinity parameter, also used for assessment and control of process stability of anaerobic digestion (Rabii et al., 2019) (P. Kumar et al., 2019), was recommended to be in the interval 1500 and $6000 \mathrm{mgCaCO}_{3} \cdot \mathrm{L}^{-1}$ of the 
reactor for assuring a stable process (Fernández-Rodríguez et al., 2019) (Fragoso et al., 2020) (Latifi et al., 2019).

Additionally, the TVFA concentrations are linked to the biodigester operation and allow it to evaluate if the hydrolytic-acidogenic effluent is convenient for the methanogenesis phase (P. Kumar et al., 2019) (Berhe \& Leta, 2019). It was determined that extremely active acidogenic microorganisms could generate a big amount of VFAs and hydrogen that can inhibit the AD process (Zealand et al., 2018). A TVFA concentration of more than 2000 $\mathrm{mg} \mathrm{L}^{-1}$ in the medium and a total ammoniacal nitrogen concentration of more than $1500 \mathrm{mg} \mathrm{L}^{-1}$ were shown to inhibit the AD (Wang et al., 2018) (P. Kumar et al., 2019). Nevertheless, another study found an AcoD process satisfactorily operating at higher proportions of acids (Ma et al., 2019) (Borowski \& Kucner, 2019).

Moreover, methanogenic bacteria were impacted at propionic acid concentrations more than $1-2 \mathrm{~g} \mathrm{~L}^{-1}$ while they can bear acetic and butyric acid density reaching $10 \mathrm{~g} \mathrm{~L}^{-1}$ (Lovato et al., 2018). Besides, it was shown that the proportion of propionic acid with acetic acid exceeding 1.4 could lead to digester failure (Kalamdhad et al., 2016).

Also, the existence of recalcitrant organic matters, including phenols, can induce process instability and diminish biogas generation effectiveness (Jingura \& Kamusoko, 2016) (Lovato et al., 2019) (Mkruqulwa, Okudoh, \& Oyekola, 2019). A substrate with higher lipids and proteins affects the AD process viscosity due to the formation of aggregates and foam in the biodigester. Therefore, the system operation can be hindered due to digester overflow and mixing system contamination (Elalami et al., 2019) (Tápparo et al., 2019). Besides, long-chain fatty acids (LCFA) and ammonium soaps with ammonia can lead to foaming (Wang et al., 2018).

Produced from the hydrolysis step, LCFA can be harmful to hydrogen-generating acetogens, and methanogenic bacteria (Kougias \& Angelidaki, 2018) because LCFA may dissolve the lipid bilayer or cause the denaturation of membrane proteins in the microbial cell. Thus, the enzyme activity may be inhibited (Chan et al., 2019) and induce cell lysis. Moreover, LCFA could penetrate the surface of the cell membrane contributing to the restriction of mass transfer (Wang et al., 2018).

As mentioned previously, hydrogen sulfide from the reduction of sulfate by sulfate-reducing bacteria is produced due to the degradation of sulfur-containing amino acids. Consequently, it inhibits the anaerobic digestion system by penetrating the bacterial cell membrane even at an extremely small quantity of $50 \mathrm{mg} \cdot \mathrm{L}^{-1}$ ( $\mathrm{Li}$ et al., 2019) (Wang et al., 2018).

Regarding the effectiveness of the substrate usage, it was shown that the enhancement of TS concentration severely affects the methane yield operation (Sukhesh et al., 2019) (E. Zhang et al., 2018).

Besides, it was demonstrated that reactors with high buffering capacity enable the stabilization of the acidification and methanization even at low S/I ratios (Ma et al., 2019) (Ngan et al., 2019). Besides, it was suggested that the amount of inoculum should be greater than that of the substrates to reach the highest degradability of the substrate (Akshaya \& Jacob, 2020).

\section{Conclusions}

The anaerobic digestion technology is increasingly interesting as an alternative method to produce energy. It is a non-polluting and environmentally friendly process. Being an improvement to mono-digestion, the AcoD was adopted to tackle all drawbacks of mono-digestion. In the present review, advancements of AcoD were shown through observations made on some factors along the process that limit the system and hence, hinder the production of biofuels. As a result, it is worth noting the complexity of the AcoD technology. Indeed, AcoD depends on many factors that should be accounted so that an optimum quantity of biofuels could be generated. Those advancements were on the choice of the composition of the substrates as well as the ratio between the substrates and the inoculum; the importance of pretreatment before the process; the control and choice of the environmental conditions including $\mathrm{pH}$, temperature, moisture content, carbon-to-nitrogen ratio, and microbial community; the choice of suitable operational parameters including hydraulic retention time, organic loading rate, and solid retention time. Moreover, a post-treatment, recently added to the process of AcoD helps upgrade and purify the biogas. Nevertheless, progressions on $\mathrm{AcoD}$ could not be made without analytical and empirical tools. Indeed, the assessment of the whole system in many aspects is easier, such as biodegradability and synergy of the substrates; the efficiency of the process; and the most important, the identification of the operation inhibitors. However, it was emphasized that there are sometimes a lot of differences in the system parameters from one digestion process to another. There are as many system parameters sets as the number of substrates combinations conducting sometimes in contradictory results and conclusions. Still, further researches should be done on $\mathrm{AcoD}$ technology to facilitate its implementation and vulgarization to switch completely to renewable 
energy which is not impossible when looking at all the progressions made in the last few years.

\section{References}

Achinas, S. \& Euverink, G. J. W. (2019). Elevated biogas production from the anaerobic co-digestion of farmhouse waste: Insight into the process performance and kinetics. Waste Management \& Research, 37(12), 1240-1249. https://doi.org/10.1177/0734242X19873383

Ahlberg-Eliasson, K., Liu, T., Nadeau, E. \& Schnürer, A. (2018). Forage types and origin of manure in co-digestion affect methane yield and microbial community structure. Grass and Forage Science, 73(3), 740-757. https://doi.org/10.1111/gfs. 12358

Ahmad, A. (2020). Process evaluation for petroleum wastewater co-digestion with rye grass to enhance methane production. Waste and Biomass Valorization, 11, 861-871. https://doi.org/10.1007/s12649-018-0473-9

Ahn, Y., Lee, W., Kang, S. \& Kim, S.-H. (2020). Enhancement of sewage sludge digestion by co-digestion with food waste and swine waste. Waste and Biomass Valorization, 11, 2421-2430. https://doi.org/10.1007/s12649-018-00558-w

Akshaya, N. B. \& Jacob, S. (2020). Unification of waste management from fish and vegetable markets through anaerobic co-digestion. Waste and Biomass Valorization, 11, 1941-1951. https://doi.org/10.1007/s12649-018-0438-z

Algapani, D. E., Qiao, W., Ricci, M., Bianchi, D., M. Wandera, S., Adani, F. \& Dong, R. (2019). Bio-hydrogen and bio-methane production from food waste in a two-stage anaerobic digestion process with digestate recirculation. Renewable Energy, 130(January), 1108-1115. https://doi.org/10.1016/j.renene.2018.08.079

Alrawashdeh, K. A. bkoor. (2019). Improving anaerobic co-digestion of sewage sludge with thermal dried olive mill wastewater. Waste and Biomass Valorization, 10, 2213-2219. https://doi.org/10.1007/s12649-018-0234-9

Alrawashdeh, K. A. bkoor \& Al-Essa, A. H. (2019). Anaerobic co-digestion mill wastewater-activated Sludge effect of aerobic pretreatment on the performance of OMW anaerobic digestion. Waste and Biomass Valorization. https://doi.org/10.1007/s12649-019-00785-9

Berhe, S. \& Leta, S. (2018). Anaerobic co-digestion of tannery wastewater and tannery solid waste using two-stage anaerobic sequencing batch reactor: Focus on performances of methanogenic step. Journal of Material Cycles and Waste Management, 20(3), 1468-1482. https://doi.org/10.1007/s10163-018-0706-9

Berhe, S. \& Leta, S. (2019). Anaerobic co-digestion of tannery wastes using two stage anaerobic sequencing batch reactor: focus on process performance of hydrolytic-acidogenic step. Journal of Material Cycles and Waste Management, 21(3), 666-677. https://doi.org/10.1007/s10163-019-00837-1

Bhatnagar, N., Ryan, D., Murphy, R. \& Enright, A. M. (2019). Effect of co-digestion ratio and enzyme treatment on biogas production from grass silage and chicken litter. Waste and Biomass Valorization, 10, 3271-3277. https://doi.org/10.1007/s12649-018-0377-8

Borowski, S. \& Kucner, M. (2019). The use of sugar beet pulp stillage for co-digestion with sewage sludge and poultry manure. Waste Management and Research, 37(10), 1025-1032. https://doi.org/10.1177/0734242X19838610

Carminati, P., Gusmini, D., Pizzera, A., Catenacci, A., Parati, K. \& Ficara, E. (2018). Biogas from mono \& co-digestion of microalgal biomass grown on piggery wastewater. Water Science \& Technology, 78(1), 103113. https://doi.org/10.2166/wst.2018.134

Cea-Barcia, G., Pérez, J. \& Buitrón, G. (2018). Co-digestion of microalga-bacteria biomass with papaya waste for methane production. Water Science \& Technology, 78(1), 125-131. https://doi.org/10.2166/wst.2018.320

Chan, P. C., Toledo, R. A. de, Iu, H. I. \& Shim, H. (2019). Effect of zinc supplementation on biogas production and short / long chain fatty acids accumulation during anaerobic co-digestion of food waste and domestic wastewater. Waste and Biomass Valorization, 10, 3885-3895. https://doi.org/10.1007/s12649-018-0323-9

Chen, H., Wei, Y., Liang, P., Wang, C., Hu, Y., Xie, M. \& Tian, H. (2020). Performance and microbial community variations of a upflow anaerobic sludge blanket (UASB) reactor for treating monosodium glutamate wastewater: Effects of organic loading rate. Journal of Environmental Management, 253(January), 1-9. https://doi.org/10.1016/j.jenvman.2019.109691

Chen, Y.-T., Yu, N., Sun, Z.-Y., Gou, M., Xia, Z.-Y., Tang, Y.-Q. \& Kida, K. (2020). Acclimation improves 
methane production from molasses wastewater with high salinity in an upflow anaerobic filter reactor: Performance and microbial community dynamics. Applied Biochemistry and Biotechnology. https://doi.org/10.1007/s12010-020-03236-7

Chuanchai, A. \& Ramaraj, R. (2018). Sustainability assessment of biogas production from buffalo grass and dung: Biogas purification and bio-fertilizer. 3 Biotech, $8(3), \quad 1-11$. https://doi.org/10.1007/s13205-018-1170-X

Colla, L. M., Margarites, A. C. F., Decesaro, A., Magro, F. G., Kreling, N., Rempel, A. \& Thaís Strieder Machado. (2019). Waste biomass and blended bioresources in biogas production. In H. Treichel \& G. Fongaro (Eds.), Improving biogas production. Biofuel and Biorefinery Technologies (pp. 1-23). 9. Springer, Cham. https://doi.org/10.1007/978-3-030-10516-7_1

Diego-Diaz, B. D. E., Cerdan, J. M. A., Penas, F. J. \& Fernandez-Rodriguez, J. (2018). Impact of supplementary nutrients on codigestion of agricultural waste: Study of temperatures. Food and Bioproducts Processing, 110(July), 120-125. https://doi.org/10.1016/j.fbp.2018.05.003

Dong, L., Cao, G., Guo, X., Liu, T., Wu, J. \& Ren, N. (2019). Efficient biogas production from cattle manure in a plug flow reactor: A large-scale long-term study. Bioresource Technology, 278(April), 450-455. https://doi.org/10.1016/j.biortech.2019.01.100

Dosta, J., Martin-Ryals, A., Garrigó, M., Ortiz-Roca, V., Fernández, I., Torres-Castillo, R. \& Mata-Álvarez, J. (2018). Acidogenic fermentation and anaerobic co-digestion of mechanically sorted OFMSW and polyethylene glycol. Waste and Biomass Valorization, 9, 2319-2326. https://doi.org/10.1007/s12649-018-0294-x

Du, S. wen, Sun, C., Ding, A. qiang, Chen, W., Zhang, M., Cheng, R. \& Wu, D. lei. (2019). Microbial dynamics and performance in a microbial electrolysis cell-anaerobic membrane bioreactor. Journal of Zhejiang University: Science A (Appl Phys \& Eng), 20(7), 533-545. https://doi.org/10.1631/jzus.A1900009

Elalami, D., Carrere, H., Monlau, F., Abdelouahdi, K., Oukarroum, A. \& Barakat, A. (2019). Pretreatment and co-digestion of wastewater sludge for biogas production: Recent research advances and trends. Renewable and Sustainable Energy Reviews, 114(October), 1-23. https://doi.org/10.1016/j.rser.2019.109287

Farhat, A., Miladi, B., Hamdi, M. \& Bouallagui, H. (2018). Fermentative hydrogen and methane co-production from anaerobic co-digestion of organic wastes at high loading rate coupling continuously and sequencing batch digesters. Environmental Science and Pollution Research, 25(28), 27945-27958. https://doi.org/10.1007/s11356-018-2796-2

Fernández-Rodríguez, M. J., Lama-Calvente, D. de la, Jiménez-Rodríguez, A., Borja, R. \& Rincón-Llorente, B. (2019). Anaerobic co-digestion of olive mill solid waste and microalga Scenedesmus quadricauda: Effect of different carbon to nitrogen ratios on process performance and kinetics. Journal of Applied Phycology, 31, 3583-3591. https://doi.org/10.1007/s10811-019-01858-x

Ferreira, S., Jr, I. V. \& Cammarota, M. C. (2018). Co-digestion of sewage sludge with crude or pretreated glycerol to increase biogas production. Environmental Science and Pollution Research, 25(22), 2181121821. https://doi.org/10.1007/s11356-018-2260-3

Fragoso, R., Carvalho, A. \& Duarte, E. (2020). Enhancement of sewage sludge bioconversion to methane by the addition of exhausted coffee biowaste liquid fraction. Waste and Biomass Valorization, 11, 1125-1130. https://doi.org/10.1007/s12649-018-0486-4

Franchi, O., Cabrol, L., Chamy, R. \& Rosenkranz, F. (2020). Correlations between microbial population dynamics, bamA gene abundance and performance of anaerobic sequencing batch reactor (ASBR) treating increasing concentrations of phenol. Journal of Biotechnology, 310(February), 40-48. https://doi.org/10.1016/j.jbiotec.2020.01.010

Gaibor-Chávez, J., Niño-Ruiz, Z., Velázquez-Martí, B. \& Lucio-Quintana, A. (2019). Viability of biogas production and determination of bacterial kinetics in anaerobic co-digestion of cabbage waste and livestock manure. Waste and Biomass Valorization, 10, 2129-2137. https://doi.org/10.1007/s12649-018-0228-7

Glanpracha, N., Basnayake, B. M. N., Eldon R. Rene, P. N. L. L. \& Annachhatre, A. P. (2018). Cyanide degradation kinetics during anaerobic co-digestion of cassava pulp with pig manure. Water Science \& Technology, 11, 1-11. https://doi.org/10.2166/wst.2018.210

González, R., Smith, R., Blanco, D., Fierro, J. \& Gómez, X. (2019). Application of thermal analysis for 
evaluating the effect of glycerine addition on the digestion of swine manure. Journal of Thermal Analysis and Calorimetry, 135(4), 2277-2286. https://doi.org/10.1007/s10973-018-7464-8

Gunes, B., Stokes, J., Davis, P., Connolly, C. \& Lawler, J. (2019). Pre-treatments to enhance biogas yield and quality from anaerobic digestion of whiskey distillery and brewery wastes: A review. Renewable and Sustainable Energy Reviews, 113(October), 1-15. https://doi.org/10.1016/j.rser.2019.109281

Hallaji, S. M., Kuroshkarim, M. \& Moussavi, S. P. (2019). Enhancing methane production using anaerobic co-digestion of waste activated sludge with combined fruit waste and cheese whey. BMC Biotechnology, 19(March), 1-10. https://doi.org/10.1186/s12896-019-0513-y

Horan, N., Yaser, A. Z. \& Wid, N. (Eds.). (2018). Anaerobic digestion processes applications and effluent treatment. Green energy and technology. Singapore: Springer Singapore. https://doi.org/10.1007/978-981-10-8129-3

Iacovidou, E. \& Voulvoulis, N. (2018). A multi-criteria sustainability assessment framework: Development and application in comparing two food waste management options using a UK region as a case study. Environmental Science and Pollution Research, 25(36), 35821-35834. https://doi.org/10.1007/s11356-018-2479-z

Ijanu, E. M., Kamaruddin, M. A. \& Norashiddin, F. A. (2020). Coffee processing wastewater treatment: A critical review on current treatment technologies with a proposed alternative. Applied Water Science, 10(11), 1-11. https://doi.org/10.1007/s13201-019-1091-9

Inayat, A., Raza, M., Ghenai, C., Shanableh, A., Said, Z., Samman, S. \& Lazkani, A. (2019). Simulation of anaerobic co-digestion process for the biogas production using Aspen Plus. In Advances in science and engineering technology international conferences (ASET) (pp. 1-5). Dubai, United Arab Emirates. https://doi.org/10.1109/ICASET.2019.8714403

Jacob-Lopes, E., Queiroz Zepka, L. \& Queiroz, M. I. (Eds.). (2018). Energy from microalgae. Green energy and technology. Cham: Springer International Publishing. https://doi.org/10.1007/978-3-319-69093-3

Jiang, Y., Dennehy, C., Lawlor, P. G., Hu, Z., Mccabe, M., Cormican, P. \& Gardiner, G. E. (2019). Exploring the roles of and interactions among microbes in dry co-digestion of food waste and pig manure using high throughput 16S rRNA gene amplicon sequencing. Biotechnology for Biofuels, 12(2), 1-16. https://doi.org/10.1186/s13068-018-1344-0

Jingura, R. M. \& Kamusoko, R. (2016). Optimisation of biogas production by anaerobic co-digestion. In R. Kumar, S. Singh \& V. Balan (Eds.). Valorization of lignocellulosic biomass in a biorefinery (pp. 143-169). New York: Nova Science Publishers.

Kalamdhad, A. S., Singh, J. \& Dhamodharan, K. (Eds.). (2016). Advances in waste management. Select proceedings of recycle 2016. Singapore: Springer Singapore. https://doi.org/10.1007/978-981-13-0215-2

Kougias, P. G. \& Angelidaki, I. (2018). Biogas and its opportunities - A review. Frontiers of Environmental Science \& Engineering, 12(3), 1-12. https://doi.org/10.1007/s11783-018-1037-8

Kumar, P., Prajapati, S. K., Malik, A. \& Vijay, V. K. (2019). Evaluation of biomethane potential of waste algal biomass collected from eutrophied lake: Effect of source of inocula, co-substrate, and VS loading. Journal of Applied Phycology, 31(1), 533-545. https://doi.org/10.1007/s10811-018-1585-0

Latha, K., Velraj, R., Shanmugam, P. \& Sivanesan, S. (2019). Mixing strategies of high solids anaerobic co-digestion using food waste with sewage sludge for enhanced biogas production. Journal of Cleaner Production, 210(February), 388-400. https://doi.org/10.1016/j.jclepro.2018.10.219

Latifi, P., Karrabi, M. \& Danesh, S. (2019). Anaerobic co-digestion of poultry slaughterhouse wastes with sewage sludge in batch-mode bioreactors (effect of inoculum-substrate ratio and total solids). Renewable and Sustainable Energy Reviews, 107(June), 288-296. https://doi.org/10.1016/j.rser.2019.03.015

Li, Y., Chen, Y. \& Wu, J. (2019). Enhancement of methane production in anaerobic digestion process: A review. Applied Energy, 240(June 2018), 120-137. https://doi.org/10.1016/j.apenergy.2019.01.243

Liu, W. \& Liao, B. (2018). Anaerobic co-Digestion of vegetable and fruit market waste in LBR + CSTR two-stage process for waste reduction and biogas production. Applied Biochemistry and Biotechnology, 188(1), 185-193. https://doi.org/10.1007/s12010-018-2910-4

Lovato, G., Albanez, R., Triveloni, M., Ratusznei, S. M. \& Rodrigues, J. A. D. (2018). Methane production by co-digesting vinasse and whey in an AnSBBR: Effect of mixture ratio and feed strategy. Applied 
Biochemistry and Biotechnology, 187(1), 28-46. https://doi.org/10.1007/s12010-018-2802-7

Lovato, G., Batista, L. P. P., Preite, M. B., Yamashiro, J. N., Becker, A. L. S., Vidal, M. F. G. \& Rodrigues, J. A. D. (2019). Viability of using glycerin as a co-substrate in anaerobic digestion of sugarcane stillage (vinasse): Effect of diversified operational strategies. Applied Biochemistry and Biotechnology, 188(July), 720-740. https://doi.org/10.1007/s12010-019-02950-1

Ma, X., Jiang, T., Chang, J., Tang, Q., Luo, T. \& Cui, Z. (2019). Effect of substrate to inoculum ratio on biogas production and microbial community during hemi-solid-state batch anaerobic co-digestion of rape straw and dairy manure. Applied Biochemistry and Biotechnology, 189(November), 884-902. https://doi.org/10.1007/s12010-019-03035-9

Martinez, E. J., Rosas, J. G., Sotres, A., Moran, A., Cara, J., Sanchez, M. E. \& Gomez, X. (2018). Co-digestion of sludge and citrus peel wastes: Evaluating the effect of biochar addition on microbial communities. Biochemical Engineering Journal, 137(september), 314-325. https://doi.org/10.1016/j.bej.2018.06.010

Mehariya, S., Patel, A. K., Obulisamy, P. K., Punniyakotti, E. \& Wong, J. W. C. (2018). Co-digestion of food waste and sewage sludge for methane production: Current status and perspective. Bioresource Technology, 265(Oktober), 519-531. https://doi.org/10.1016/j.biortech.2018.04.030

Mkruqulwa, U., Okudoh, V. \& Oyekola, O. (2019). Optimizing methane production from co-digestion of cassava biomass and winery solid waste using response surface methodology. Waste and Biomass Valorization. https://doi.org/10.1007/s12649-019-00801-y

Mozhiarasi, V., Speier, C. J., Rose, P. M. B., Mondal, M. M., Pragadeesh, S., Weichgrebe, D. \& Srinivasan, S. V. (2019). Variations in generation of vegetable, fruit and flower market waste and effects on biogas production, exergy, and energy contents. Journal of Material Cycles and Waste Management, 21(3), 713728. https://doi.org/10.1007/s10163-019-00828-2

Muske, A. N. \& Rao, P. V. (2019). Evaluation of biogas production potential by anaerobic co-digestion with substrate mixture of fruit waste, lawn grass, and manures. In R. M., C. S., P. K. \& M. U. (Eds.). Water resources and environmental engineering II (pp. 91-99). Singapore: Springer. https://doi.org/10.1007/978-981-13-2038-5

Náthia-Neves, G., Berni, M., Dragone, G., Mussatto, S. I. \& Forster-Carneiro, T. (2018). Anaerobic digestion process: Technological aspects and recent developments. International Journal of Environmental Science and Technology, 15(9), 2033-2046. https://doi.org/10.1007/s13762-018-1682-2

Ngan, N. V. C., Chiem, N. H., Nam, T. S., Viet, L. H. \& Ingvorsen, K. (2019). Rice straw: An alternative for energy generation by anaerobic co-digestion to pig manure. In M. A. Stewart \& P. A. Coclanis (Eds.). Water and power, advances in global change research (pp. 153-172). 64. Springer, Cham. https://doi.org/10.1007/978-3-319-90400-9_9

Oliveira, J. V, Duarte, T., Costa, J. C., Cavaleiro, A. J., Pereira, M. A. \& Alves, M. M. (2018). Improvement of biomethane production from sewage sludge in co-digestion with glycerol and waste frying oil, using a design of experiments. BioEnergy Research, 11(4), 763-771. https://doi.org/10.1007/s12155-018-9933-0

Orfanoudaki, A., Maragkaki, G. M. A., Kallithrakas, M. S. F. N. G. \& Manios, K. T. (2019). Anaerobic co-digestion of pig manure and spent coffee grounds for enhanced biogas production. Waste and Biomass Valorization. https://doi.org/10.1007/s12649-019-00796-6

Patinvoh, R. J., Lundin, M., Taherzadeh, M. J. \& Sárvári, I. (2020). Dry anaerobic co-digestion of citrus wastes with keratin and lignocellulosic wastes: Batch and continuous processes. Waste and Biomass Valorization, 11, 423-434. https://doi.org/10.1007/s12649-018-0447-y

Pradhan, B. (Ed.). (2017). GCEC 2017 Proceedings of the 1st global civil engineering conference. Lecture notes in civil engineering (vol. 9). Singapour: Springer Singapore. https://doi.org/10.1007/978-981-10-8016-6

Qi, Y. \& Chapman, T. (2018). Mixing and transport. Water Environment Research, 90(10), 1719-1722. https://doi.org/10.2175/106143018X15289915807380

Rabii, A., Aldin, S., Dahman, Y. \& Elbeshbishy, E. (2019). A review on anaerobic co-digestion with a focus on the microbial populations and the effect of multi-stage digester configuration. Energies, 12(6), 1-25. https://doi.org/10.3390/en12061106

Ribera, J., Marina, P., Fabregat, B., Calderer, M., Polášková, M., Svojitka, J. \& Rovira, M. (2020). Anaerobic membrane bioreactor (AnMBR) for the treatment of cheese whey for the potential recovery of water and 
energy. Waste and Biomass Valorization, 11, 1821-1835. https://doi.org/10.1007/s12649-018-0482-8

Romagnoli, F., Dorella, M., Gruduls, A., Collotta, M. \& Tomasoni, G. (2019). Anaerobic co-digestion of baltic seaweeds with wheat straw and straw pellets: Synergetic effects on biomethane yield and kinetic biodegradability constant. $\quad$ Energy $\quad$ Procedia, $\quad$ 158(February), https://doi.org/10.1016/j.egypro.2019.01.221

Sahoo, S. R. \& Rao, P. V. (2019). Temperature-phased anaerobic co-digestion of food waste and rice husk using response surface methodology. In R. M., C. S., P. K. \& M. U. (Eds.). Water resources and environmental engineering II (pp. 137-146). Singapour: Springer. https://doi.org/10.1007/978-981-13-2038-5

Salama, E., Saha, S., Kurade, M. B., Dev, S., Woong, S. \& Jeon, B. (2019). Recent trends in anaerobic co-digestion: Fat, oil, and grease (FOG) for enhanced biomethanation. Progress in Energy and Combustion Science, 70(January), 22-42. https://doi.org/10.1016/j.pecs.2018.08.002

Sarwar, R., Elbeshbishy, E. \& Parker, W. J. (2018). Codigestion of high-pressure thermal hydrolysis-treated thickened waste activated sludge with primary sludge in two-stage anaerobic digestion. Environmental Progress \& Sustainable Energy, 37(1), 425-433. https://doi.org/10.1002/ep.12700

Shahbaz, M., Ammar, M., Zou, D., Korai, R. M. \& Li, X. (2018). An insight into the anaerobic co-digestion of municipal solid waste and food waste: Influence of co-substrate mixture ratio and substrate to inoculum ratio on biogas production. Applied Biochemistry and Biotechnology, 187(4), 1356-1370. https://doi.org/10.1007/s12010-018-2891-3

Shen, F., Zhong, B., Wang, Y., Xia, X., Zhai, Z. \& Zhang, Q. (2019). Cellulolytic microflora pretreatment increases the efficiency of anaerobic co-digestion of rice straw and pig manure. BioEnergy Research, 12(September), 703-713. https://doi.org/10.1007/s12155-019-10013-w

Siddique, M. N. I. \& Wahid, Z. A. (2018). Achievements and perspectives of anaerobic co-digestion: A review. Journal of Cleaner Production, 194(September), 359-371. https://doi.org/10.1016/j.jclepro.2018.05.155

Sittijunda, S. \& Reungsang, A. (2020). Methane production from the co-digestion of algal biomass with crude glycerol by anaerobic mixed cultures. Waste and Biomass Valorization, 11, 1873-1881. https://doi.org/10.1007/s12649-018-0542-0

Solé-bundó, M., Passos, F., Romero-güiza, M. S., Ferrer, I. \& Astals, S. (2019). Co-digestion strategies to enhance microalgae anaerobic digestion: A review. Renewable and Sustainable Energy Reviews, 112(May), 471-482. https://doi.org/10.1016/j.rser.2019.05.036

Song, L., Li, D., Fang, H., Cao, X., Liu, R., Niu, Q. \& Li, Y.-Y. (2019). Revealing the correlation of biomethane generation, DOM fluorescence, and microbial community in the mesophilic co-digestion of chicken manure and sheep manure at different mixture ratio. Environmental Science and Pollution Research, 14(January), 19411-19424. https://doi.org/10.1007/s11356-019-05175-1

Sukhesh, M. J., Muske, A. \& Rao, P. V. (2019). Multi-substrate anaerobic co-digestion of citrus pulp, lawn grass, and chicken manure - A batch study. Environmental Progress \& Sustainable Energy, 8, 1-8. https://doi.org/10.1002/ep.13153

Sukhesh, M. J. \& Rao, P. V. (2018). Synergistic effect in anaerobic co-digestion of rice straw and dairy manure A batch kinetic study. Energy Sources, Part A: Recovery, Utilization, and Environmental Effects, 41(17), 2145-2156. https://doi.org/10.1080/15567036.2018.1550536

Tápparo, D. C., Amaral, A. C. do, Steinmetz, R. L. R. \& Kunz, A. (2019). Co-digestion of animal manure and carcasses to increase biogas generation. In H. Treichel \& G. Fongaro (Eds.). Improving biogas production. Biofuel and biorefinery technologies (pp. 99-116). 9. Springer, Cham. https://doi.org/10.1007/978-3-030-10516-7_5

Terada, A. (2018). Significance of co-digestion as energy recovery at a sewage treatment plant amenable to a shrinking population. Clean Technologies and Environmental Policy, 20(5), 909-910. https://doi.org/10.1007/s10098-018-1554-y

Tišma, M., Planinić, M., Bucić-Koöić, A., Panjičko, M., Zupančič, G. D. \& Zelić, B. (2018). Corn silage fungal-based solid-state pretreatment for enhanced biogas production in anaerobic co-digestion with cow manure. Bioresource Technology, 253(April), 220-226. https://doi.org/10.1016/j.biortech.2018.01.037

Tong, H., Tong, Y.-W. \& Peng, Y. H. (2019). A comparative life cycle assessment on mono- and co-digestion of food waste and sewage sludge. Energy Procedia, 158(February), 4166-4171. 
https://doi.org/10.1016/j.egypro.2019.01.814

Tyagi, V. K., Fdez-Güelfo, L. A., Zhou, Y., Álvarez-Gallego, C. J., Garcia, L. I. R. \& Ng, W. J. (2018). Anaerobic co-digestion of organic fraction of municipal solid waste (OFMSW): Progress and challenges. Renewable and Sustainable Energy Reviews, 93(C), 380-399. https://doi.org/10.1016/j.rser.2018.05.051

Uma, S., Thalla, A. K. \& Devatha, C. P. (2020). Co-digestion of food waste and switchgrass for biogas potential: Effects of process parameters. Waste and Biomass Valorization, 11, 827-839. https://doi.org/10.1007/s12649-018-0508-2

Vaidya, R., Boardman, G. D., Novak, J. T., Wimmer, R. \& Hanna, M. (2018). Effect of high strength food wastes on anaerobic codigestion of sewage sludge. Water Environment Research, (April), 293-306. https://doi.org/10.2175/106143017X14902968254908

Vassalle, L., Díez-Montero, R., Machado, A. T. R., Moreira, C., Ferrer, I., Filho, C. R. M. \& Passos, F. (2019). Upflow anaerobic sludge blanket in microalgae-based sewage treatment: Co-digestion for improving biogas production. Bioresource Technology, 300. https://doi.org/10.1016/j.biortech.2019.122677

Venturin, B., Bonatto, C., Damaceno, F. M., Mulinari, J., Fongaro, G. \& Treichel, H. (2019). Physical, chemical, and biological substrate pretreatments to enhance biogas yield. In H. Treichel \& G. Fongaro (Eds.). Improving biogas production. Biofuel and biorefinery technologies (pp. 25-44). 9. Cham: Springer. https://doi.org/10.1007/978-3-030-10516-7_2

Wang, S., Jena, U. \& Das, K. C. (2018). Biomethane production potential of slaughterhouse waste in the United $\begin{array}{llll}\text { States. Energy Conversion and Management, 143-157. } & \text { 17uly), }\end{array}$ https://doi.org/10.1016/j.enconman.2018.07.059

Wei, L., Qin, K., Ding, J., Xue, M., Yang, C., Jiang, J. \& Zhao, Q. (2019). Optimization of the co-digestion of sewage sludge, maize straw and cow manure: Microbial responses and effect of fractional organic characteristics. Scientific Reports, 9(January), 1-10. https://doi.org/10.1038/s41598-019-38829-8

Wickramaarachchi, A. L., Rathnasiri, P. G., Narayana, M., Torrijos, M. \& Escudie, R. (2019). Kinetic modeling of dry anaerobic co-digestion of lignocellulosic biomass. In 2019 Moratuwa engineering research conference (MERCon) (pp. 193-198). Moratuwa, Sri Lanka. https://doi.org/10.1109/MERCon.2019.8818752

Yang, J., Wang, D., Luo, Z., Zeng, W. \& Huang, H. (2020). The role of reflux time in a leach bed reactor coupled with a methanogenic reactor for anaerobic digestion of pig manure: Reactor performance and microbial community. Journal of Cleaner Production, 242(January). https://doi.org/10.1016/j.jclepro.2019.118367

Yang, Q., Wu, B., Yao, F., He, L., Chen, F., Ma, Y. \& Li, Á. D. W. Á. X. (2019). Biogas production from anaerobic co-digestion of waste activated sludge: Co-substrates and influencing parameters. Reviews in Environmental Science and Bio/Technology, 18(4), 771-793. https://doi.org/10.1007/s11157-019-09515-y

Yu, J., Zhao, L., Feng, J., Yao, Z., Huang, K., Luo, J. \& Chen, J. (2019). Sequencing batch dry anaerobic digestion of mixed feedstock regulating strategies for methane production: Multi-factor interactions among biotic and abiotic characteristics. Bioresource Technology, 284(July), 276-285. https://doi.org/10.1016/j.biortech.2019.03.141

Yu, M., Gao, M., Wang, L., Ren, Y., Wu, C., Ma, H. \& Wang, Q. (2018). Kinetic modelling and synergistic impact evaluation for the anaerobic co-digestion of distillers' grains and food waste by ethanol pre-fermentation. Environmental Science and Pollution Research, 25(30), 30281-30291. https://doi.org/10.1007/s11356-018-3027-6

Zealand, A. M., Mei, R., Papachristodoulou, P., Roskilly, A. P., Liu, W. T. \& Graham, D. W. (2018). Microbial community composition and diversity in rice straw digestion bioreactors with and without dairy manure. Applied Microbiology and Biotechnology, 102(19), 8599-8612. https://doi.org/10.1007/s00253-018-9243-7

Zhang, E., Li, J., Zhang, K., Wang, F., Yang, H., Zhi, S. \& Liu, G. (2018). Anaerobic digestion performance of sweet potato vine and animal manure under wet, semi - dry, and dry conditions. AMB Express, 8(1), 1-10. https://doi.org/10.1186/s13568-018-0572-9

Zhang, J., Loh, K. C., Lee, J., Wang, C. H., Dai, Y. \& Wah Tong, Y. (2017). Three-stage anaerobic co-digestion of food waste and horse manure. Scientific Reports, 7(1), 1-10. https://doi.org/10.1038/s41598-017-01408-w

Zhang, M., Gao, M., Yue, S., Zheng, T., Gao, Z., Ma, X. \& Wang, Q. (2018). Global trends and future prospects 
of food waste research: A bibliometric analysis. Environmental Science and Pollution Research, 25(25), 24600-24610. https://doi.org/10.1007/s11356-018-2598-6

Zhou, H. \& Wen, Z. (2019). Solid-State anaerobic digestion for waste management and biogas production. Advances in Biochemical Engineering Biotechnology, 169, 147-168. https://doi.org/10.1007/10_2019_86

\section{Copyrights}

Copyright for this article is retained by the author(s), with first publication rights granted to the journal.

This is an open-access article distributed under the terms and conditions of the Creative Commons Attribution license (http://creativecommons.org/licenses/by/3.0/). 